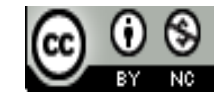

Jurnal Bimbingan Konseling Indonesia is licensed under

A Creative Commons Attribution-Non Commercial 4.0 International License.

\title{
EFEKTIVITAS TEKNIK SOSIODRAMA MELALUI BIMBINGAN KELOMPOK UNTUK MENINGKATKAN PENYESUAIAN SOSIAL SISWA
}

\author{
Maria Ulfa ${ }^{1)}$, Wa Ode Husniah ${ }^{2)}$ \\ 1) Prodi Bimbingan dan Konseling, FKIP UM. Buton, Baubau, Indonesia \\ E-mail:ulfa.razak88@gmail.com ${ }^{I)}$ \\ 2) Prodi Bimbingan dan Konseling, FKIP UM. Buton, Baubau, Indonesia \\ E-mail: odehusniah@gmail.com ${ }^{2}$
}

\begin{abstract}
Abstrak. Tujuan penelitian ini untuk mengetahui dan mendeskripsikan efektivitas teknik sosiodrama untuk meningkatkan penyesuaian sosial siswa kelas VIII SMP Negeri 4 Pasarwajo. Pendekatan penelitian yang digunakan dengan pendekatan kuantitatif pre-experimental dengan one group pretest posttest design. Penentuan sampel melalui teknik sampling purpossive dengan jumlah sampel 8 siswa. Berdasarkan hasil uji penelitian, tingkat penyesuaian sosial siswa setelah diberikan teknik sosiodrama melalui layanan bimbingan kelompok mengalami peningkatan. Hal tersebut terlihat pada perubahan peningkatan skor penyesuaian sosial siswa sebelum diberikan treatment/perlakuan pretest dan posttest sebesar 237 atau $11.8 \%$. Diperkuat dengan hasil analisis uji test statistik uji wilcoxon dengan masing-masing pretest posttest yang menunjukkan nilai hitung sebesar 0.012, sehingga dapat disimpulkan bahwa teknik sosiodrama efektif untuk meningkatkan penyesuaian sosial pada siswa.
\end{abstract}

Kata Kunci: Sosiodrama; Penyesuaian sosial; Bimbingan Kelompok

\section{Pendahuluan}

Memiliki penyesuaian sosial yang baik, sangat berpengaruh terhadap lingkungan sosial kehidupan. Penyesuaian sosial dibutuhkan oleh setiap individu untuk menjadikan dirinya sebagai manusia dengan segala ciri kemanusiaannya, karena tak ada manusia yang mampu hidup tanpa manusia lain [1]. Individu yang memiliki penyesuaian sosial yang baik, akan membentuk kepercayaan diri individu, sikap obyektif, saling memahami, meningkatkan sikap asertif serta memiliki hubungan yang baik dengan lingkungan sekitarnya. Sementara individu yang memiliki pernyesuaian sosial yang kurang baik (rendah), akan berdampak pada kepribadian individu itu sendiri, seperti adanya ketidakbahagiaan dan ketidakpuasan terhadap dirinya sendiri, serta tidak mampu menerima kenyataan hidup yang sedang dijalani. Dalam hal ini sudah jelas bahwa individu harus dapat hidup sesuai dengan tuntutan lingkungan sekitar dan juga sesuai dengan kemampuan dirinya artinya hubungan penyesuaian diri individu diperlukan, untuk menjalankan tugas perekembangan dengan baik. Penyesuaian sosial merupakan bagian dari penyesuaian diri
Hasil wawancara peneliti dengan guru mata pelajaran dan bimbingan konseling sekolah menjelaskan bahwa sebagian dari siswa kelas VIII SMP Negeri 4 Pasarwajo memang kurang memiliki penyesuaian sosial terkhusus di lingkungan sekolah. Siswa kurang telibat kejasama baik kelompok di luar kelas maupun pada saat belajar kelompok di dalam kelas, siswa pasif ketika mengikuti proses belajar mengajar dikelas, kurangnya kepercayaan diri yang pada akhirnya menyebabkan siswa tidak dapat melatih dan mengembangkan potensi yang dimilikinya dan sulit menyesuaikan dirinya dengan lingkungannya.

Untuk meningkatkan penyesuaian sosial tersebut, peneliti menerapkan pemberian layanan bimbingan kelompok. Dalam pemberian layanan bimbingan dan konseling di sekolah terdapat teknik-teknik bimbingan dan konseling yang digunakan untuk menangani dan mengatasi masalah yang dihadapi oleh siswa. Adapun teknik bimbingan konseling yang digunakan dalam penelitian ini yaitu dengan menggunakan teknik sosiodrama melalui bimbingan kelompok (BKp). Dalam layanan bimbingan kelompok siswa akan membahas topik penyesuaian sosial dengan melakukan sosiodrama dan berdiskusi bersama-sama. 
Prayitno dalam [2] mengemukakan bahwa layanan bimbingan kelompok merupakan suatu kegiatan yang dilakukan oleh sekelompok individu yang memanfaatkan dinamika kelompok, artinya semua individu yang menjadi anggota kelompok akan saling berinteraksi, bertukar pikiran, bebas mengemukakan pendapat, dan saling berbagi informasi yang bermanfaat. Bimbingan kelompok berupaya untuk merubah sikap dalam perilaku secara langsung melalui pemberian informasi yang menekankan pengelolaan kognitif kepada anggota kelompok. Sosiodrama yang merupakan sebagai salah satu teknik dalam bimbingan kelompok melibatkan pembagian peran disertai adanya konflik-konflik individu dan sosial yang diceritakan, dalam sosiodrama yang dieksplorasi adalah watak manusia, problem manusia, dan cara mengatasi problem-problem itu [3]. Untuk meningkatkan sikap penyesuaian sosial, dalam proses penelitian ini akan lebih banyak dilakukan oleh siswa-siswa yang akan bermain peran. Berdasarkan uraian tersebut, peneliti beranggapan bahwa teknik sosiodrama ini penting dalam meningkatkan penyesuaian sosial siswa.

\section{METODE}

Pendekatan penelitian yang digunakan adalah pendekatan kuantitatif, dengan menggunakan desain penelitian metode pre-experimental dengan bentuk one-group pretest-postest design, yaitu desain yang terdapat pretest sebelum diberikan perlakuan, dengan demikian hasil perlakuan dapat diketahui lebih akurat, karena dapat membandingkan dengan keadaan sebelum diberi perlakuan [4]. Cara pengambilan sampel dengan teknik nonprobability sampling menggunakan teknik penentuan jumlah sampel melalui purposive sampling yaitu teknik penentuan sampel yang dengan pertimbangan tertentu [5]. Subyek penelitian ini adalah SMP Negeri 4 Pasarwajo. Obyek penelitiannya adalah Siswa kelas VIII SMP Negeri 4 Baubau. Uji Wilcoxon digunakan sebagai teknik analisis data dalam penelitian ini. Penelitian dilaksanakan dalam tiga tahap kegiatan, yaitu:

1. Tahap persiapan yaitu merumuskan masalah, menyiapkan dan menurunkan kuesioner penyesuaian sosial, prosedur mengumpulkan data, menentukan sampel penelitian, dan prosedur analisis data yang digunakan.

2. Tahap kegiatan yaitu tahap pemberian treatmen/perlakuan melalui bimbingan kelompok dengan menerapkan teknik sosiodrama untuk meningkatkan penyesuaian sosial siswa

3. Tahap Penutup yaitu dengan kembali menurunkan kuesioner setelah diberikan teknik sosiodrama untuk mengetahui tingkat perubahan, mengumpulkan dan menganalisis data serta menarik kesimpulan dari data yang telah dikumpulkan.

\section{HASIL DAN PEMBAHASAN}

\section{A. HASIL}

Untuk mengetahui tinggi rendahnya penyesuaian sosial diukur melalui skala sikap yang terdiri dari 4 aspek yang dijabarkan dalam 48 aitem dan 24 aitem yang teruji validitasnya dengan jumlah siswa 68 siswa. Proses uji validitas dan reliabilitas dilakukan dengan professional judgment (dengan cara meminta pertimbangan kepada ahli untuk mengetahui sejauhmana aitem-aitem telah mencerminkan apa yang diukur). Berdasarkan 24 aitem yang valid dengan rit atau indeks daya beda aitem antara 0,348 sampai dengan 0,631 , dan rerata indeks daya beda sebesar 0,455. Dan hasil pengujian reliabilitas menggunakan teknik alpha Cronbach, diketahui bahwa indeks reliabilitas skala penyesuaian sosial 0,876 dengan jumlah aitem keseluruhan 24 aitem, berarti skor skala tersebut menunjukkan $87,6 \%$ merupakan variasi yang terjadi pada skor yang sesungguhnya pada kelompok subyek bersangkutan, atau dengan kata lain bahwa $12,4 \%$ dari perbedaan skor tersebut maka muncul akibat variasi error atau kesalahan dalam pengukuran. Kategori yang digunakan didasarkan pada standar deviasi dan mean hipotetik yaitu dengan kategorisasi jenjang berdasarkan distribusi normal dengan kategorisasi tinggi, sedang dan rendah [6]. Berdasarkan studi awal melalui observasi serta mengkaji penelitian terdahulu, penerapan teknik sosiodrama melalui bimbingan kelompok untuk meningkatkan penyesuaian sosial siswa diinternalisasikan dengan mengintegrasikan permasalahan-permasalahan sesuai aspekaspek penyesuaian sosial seperti tabel I berikut ini

TABEL I

INDIKATOR, SASARAN DAN TREATMENT

\begin{tabular}{|c|c|c|c|c|}
\hline $\begin{array}{l}\text { Pelaksanaan } \\
\text { Kegiatan }\end{array}$ & Target intervensi & Tujuan & Kegiatan & Indikator Keberhasilan \\
\hline $\begin{array}{l}\text { Kegiatan } \\
\text { Pendahuluan }\end{array}$ & $\begin{array}{ll}\checkmark & \text { Persiapan mengikuti } \\
& \text { kegiatan } \\
\checkmark & \text { Merumuskan tujuan } \\
& \text { yang dicapai } \\
\checkmark & \text { Identifikasi (Pretest) }\end{array}$ & $\begin{array}{ll}\checkmark & \text { Menciptakan } \\
& \text { hubungan yang baik } \\
& \text { antara peneliti dengan } \\
& \text { anggota kelompok } \\
\checkmark & \text { Menyusun tujuan } \\
& \text { pelaksanaan } \\
& \text { bimbingan kelompok } \\
\checkmark & \text { Mendeskripsikan dan } \\
\text { mengetahui gambaran } \\
\text { umum penyesuaian } \\
\text { sosial siswa }\end{array}$ & $\begin{array}{ll}\checkmark & \text { Mengajak siswa untuk } \\
& \text { terlibat aktif dalam } \\
& \text { BBk tanpa perasaan } \\
& \text { keterpaksaan } \\
\checkmark & \text { Mengisi dengan baik } \\
& \text { skala sikap } \\
\text { penyesuaian sosial }\end{array}$ & $\begin{array}{ll}\checkmark & \text { Siswa bersedia } \\
& \text { mengikuti BBk } \\
\checkmark & \text { Adanya kesepakatan } \\
\text { antara konseli dan } \\
\text { peneliti untuk } \\
\text { mencapai tujuan } \\
\text { pelaksanaan BBk } \\
\checkmark \text { Skala/ Quesioner } \\
\text { yang telah diisi }\end{array}$ \\
\hline
\end{tabular}




\begin{tabular}{|c|c|c|c|c|c|c|c|c|}
\hline BBp 1 & $\checkmark$ & Penampilan nyata & $\begin{array}{l}\checkmark \\
\checkmark\end{array}$ & $\begin{array}{l}\text { Mampu } \\
\text { mengaktualisasi diri } \\
\text { Kemampuan dalam } \\
\text { menjalin hubungan } \\
\text { komunikasi antar } \\
\text { manusia } \\
\text { Mampu bersikap } \\
\text { terbuka terhadap orang } \\
\text { lain. }\end{array}$ & $\checkmark$ & $\begin{array}{l}\text { Memainkan peran, } \\
\text { sejauh mana siswa } \\
\text { mampu } \\
\text { mengaktualisasikan } \\
\text { dirinya } \\
\text { Kemampuan menjalin } \\
\text { hubungan komunikasi } \\
\text { antar individu } \\
\text { kesediaan untuk terbuka } \\
\text { pada orang lain }\end{array}$ & $\checkmark$ & $\begin{array}{l}\text { Siswa mampu } \\
\text { memainkan peran } \\
\text { dengan } \\
\text { mengaktualisasikan } \\
\text { dirinya } \\
\text { Siswa mampu } \\
\text { menjalin hubungan } \\
\text { antar individu } \\
\text { Siswa bersedia untuk } \\
\text { terbuka pada orang } \\
\text { lain }\end{array}$ \\
\hline BBp 2 & $\checkmark$ & $\begin{array}{l}\text { Penyesuaian } \\
\text { Terhadap Kelompok }\end{array}$ & $\begin{array}{l}\checkmark \\
\checkmark \\
\checkmark\end{array}$ & $\begin{array}{l}\text { Dapat bekerjasama } \\
\text { Memiliki rasa } \\
\text { tanggung jawab } \\
\text { Memiliki kesetia } \\
\text { kawanan }\end{array}$ & $\checkmark$ & $\begin{array}{l}\text { Memainkan peran, } \\
\text { menumbuhkan sikap } \\
\text { kerjasama, tanggung } \\
\text { jawab dan } \\
\text { kesetiakawanan }\end{array}$ & $\checkmark$ & $\begin{array}{l}\text { Siswa mampu } \\
\text { memainkan peran, } \\
\text { dan mampu } \\
\text { bekerjasama, serta } \\
\text { tanggung jawab dan } \\
\text { memiki rasa } \\
\text { kesetiakawanan }\end{array}$ \\
\hline BBp 3 & $\checkmark$ & Sikap Sosial & $\begin{array}{l}\checkmark \\
\checkmark\end{array}$ & $\begin{array}{l}\text { Berpartisipasi di } \\
\text { lingkungan sekitar } \\
\text { dalam kegiatan sosial } \\
\text { Memiliki sikap empati } \\
\text { Menghormati dan } \\
\text { menghargai pendapat } \\
\text { antar sesame }\end{array}$ & $\checkmark$ & $\begin{array}{l}\text { Memainkan peran } \\
\text { dengan ikut serta di } \\
\text { lingkungan sekitarnya } \\
\text { dalam kegiatan sosial } \\
\text { Menunjukkan sikap } \\
\text { empati/belas kasih } \\
\text { pada individu } \\
\text { Menunjukkan sikap } \\
\text { menghargai dan } \\
\text { menghormati pendapat } \\
\text { antar sesama }\end{array}$ & $\checkmark$ & $\begin{array}{l}\text { Siswa mampu } \\
\text { menunjukkan keikut } \\
\text { sertaan dirinya di } \\
\text { lingkungan } \\
\text { sekitarnya dalam } \\
\text { kegiatan sosial } \\
\text { Siswa menunjukkan } \\
\text { sikap empati } \\
\text { Siswa menunjukkan } \\
\text { sikap saling } \\
\text { menghargai dan } \\
\text { menghormati } \\
\text { pendapat antar } \\
\text { sesama }\end{array}$ \\
\hline BBp 4 & $\checkmark$ & Kepuasan Pribadi & $\begin{array}{l}\checkmark \\
\checkmark \\
\checkmark\end{array}$ & $\begin{array}{l}\text { Meningkatkan } \\
\text { kepercayaan diri } \\
\text { Meningkatkan disiplin } \\
\text { diri } \\
\text { Memiliki kehidupan } \\
\text { bermakna dan terarah }\end{array}$ & $\checkmark$ & $\begin{array}{l}\text { Memainkan peran } \\
\text { dengan penuh percaya } \\
\text { diri, } \\
\text { Mampu mengatur diri } \\
\text { untuk lebih taat dengan } \\
\text { peraturan yang dapat } \\
\text { meningkatkan disiplin } \\
\text { dirinya } \\
\text { Menunjukkan hidup } \\
\text { yang memberi arti bagi } \\
\text { kehidupan orang lain }\end{array}$ & $\begin{array}{l}\checkmark \\
\checkmark\end{array}$ & $\begin{array}{l}\text { Siswa mampu } \\
\text { memainkan peran } \\
\text { dengan rasa percaya } \\
\text { diri, } \\
\text { Siswa mampu } \\
\text { mendisiplinkan diri } \\
\text { siswa bermanfaat } \\
\text { bagi orang lain serta } \\
\text { memiliki tujuan } \\
\text { hidup yang terarah }\end{array}$ \\
\hline $\begin{array}{l}\text { Evaluasi dan } \\
\text { Tindak Lanjut }\end{array}$ & $\checkmark$ & $\begin{array}{l}\text { Kesiapan siswa } \\
\text { mengakhiri kegiatan } \\
\text { kelompok } \\
\text { Postest }\end{array}$ & $\checkmark$ & $\begin{array}{l}\text { Mengetahui perbedaan } \\
\text { penyesuaian sosial } \\
\text { setelah diberikan } \\
\text { perlakuan }\end{array}$ & $\checkmark$ & $\begin{array}{l}\text { Siswa mengisi } \\
\text { Quesioner }\end{array}$ & $\checkmark$ & $\begin{array}{l}\text { Siswa mampu } \\
\text { menerapkan } \\
\text { keterampilan yang } \\
\text { diperoleh dari BBp } \\
\text { Penyesuaian sosial } \\
\text { menjadi meningkat }\end{array}$ \\
\hline
\end{tabular}

Penggunaan uji Wilcoxon dalam penelitian ini untuk menguji signifikansi atau kemaknaan hipotesis komparatif dua sampel yang dependen (berpasangan) dengan data yang berskala ordinal [7], dalam hal ini untuk menguji efektivitas teknik sosiodrama melalui layanan bimbingan kelompok untuk meningkatkan penyesuaian sosial siswa. Melalui layanan bimbingan kelompok, siswa akan diukur penyesuaian sosialnya dengan teknik sosiodrama. Setelah pemberian perlakuan yang selanjutnya skor masing-masing subyek dibandingkan antara sebelum (pre-test) dan sesudah penerapan teknik sosiodrama (post-test). Analisis data dengan uji Wilcoxon merupakan uji non parametrik yang mengukur signifikansi perbedaan (komparasi) antara 2 kelompok data berpasangan yang berskala ordinal dan numerik (interval/rasio), serta uji 
Wilcoxon ini juga merupakan uji alternatif dari uji paired $T$ test apabila tidak memenuhi asumsi normalitasnya [8], maka dari itu dalam penelitian ini tidak diperlukan data yang berdistribusi normal. Berikut ini tabel hasil uji Wilcoxon dibantu dengan program SPSS 20 for windows.

TABEL II

HASIL UJI WILCOXON

\begin{tabular}{ccc}
\hline Kelompok & $\mathbf{Z}$ & $\begin{array}{c}\text { Asymp. Sig. } \\
\text { (2-tailed) }\end{array}$ \\
\hline Pretest-Postest & $-2.524^{\mathrm{b}}$ & 0.012 \\
\hline
\end{tabular}

Hasil analisis uji test statistik melalui uji wilcoxon dengan 8 sampel masing-masing pretest posttest menunjukkan ada perbedaan skor sebelum diberikan teknik sosiodrama dan sesudah diberikan teknik sosiodrama. Jika didasarkan pada uji analisis, nilai signifikasi sebesar $0.012<0.05$ atau $(\mathrm{p}<0.05)$, yang berarti ada perbedaan penyesuaian sosial sebelum pretest dan setelah diberikan teknik sosiodrama (posttest). Maka peneliti berkesimpulan bahwa teknik sosiodrama melalui layanan bimbingan kelompok efektif untuk meningkatkan penyesuaian sosial siswa.

Efektivitas teknik sosiodrama melalui layanan bimbimgan kelompok tampak pada meningkatnya penyesuaian sosial siswa yang didasarkan pada hasil prestest sebelum penerapan perlakuan (teknik sosiodrama) dan hasil postest setelah penerapan teknik (treatment). Berikut hasil perbandingan skor pretest dan postest secara rinci yang ditampilkan dalam tabel III dan grafik 1 .

TABEL III

PERBANDINGAN HASIL PRETEST DAN POSTEST

\begin{tabular}{cccc}
\hline No & Inisial & Pretest & Postest \\
\hline 1 & Rt & 45 & 76 \\
2 & It & 42 & 82 \\
3 & Yu & 46 & 83 \\
4 & Hi & 42 & 71 \\
5 & LO & 42 & 61 \\
6 & RK & 42 & 73 \\
7 & JY & 44 & 62 \\
8 & FE & 42 & 74 \\
\hline \multicolumn{4}{r}{ Total } \\
\hline
\end{tabular}

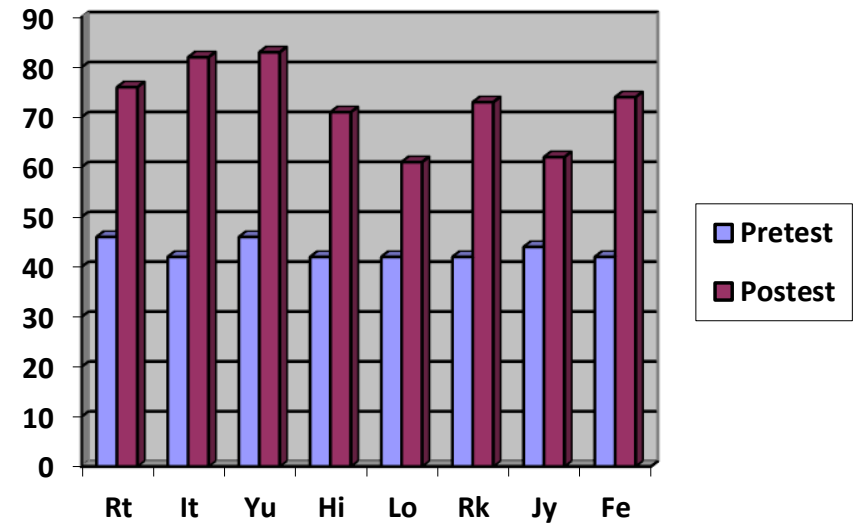

Grafik 1. Hasil perbandingan pretest dan postest skala penyesuaian sosial

Berdasarkan tabel III dan grafik 1, terlihat bahwa ada perbedaan skor pretest sebelum penerapan teknik sosiodrama dan skor postest sesudah penerapan teknik sosiodrama melalui bimbingan kelompok.

Secara menyeluruh, skor penyesuaian sosial siswa mengalami peningkatan sebesar 237 skor atau sebesar $11,8 \%$. Peningkatan skor penyesuaian sosial siswa tidak terlepas dari proses penerapan teknik sosiodrama. Adanya kesediaan dan kesiapan diri siswa untuk memerankan peran dan menerapkan hal-hal baru serta memeproleh manfaat selama berpartisipasi dalam kegiatan bimbingan kelompok teknik sosiodrama yang memberikan konstribusi pada peningkatan skor penyesuaian sosial.

\section{B. PEMBAHASAN}

Hurlock dalam [9] mendefinisikan penyesuaian sosial sebagai keberhasilan seseorang untuk menyesuaikan diri terhadap orang lain pada umumnya dan terhadap kelompok khususnya. Hampir sama dengan Schneider dalam [10] menjelaskan bahwa penyesuaian sosial adalah adanya keinginan dalam diri sesorang untuk dapat menyesuaikan diri dengan lingkungan sekitarnya melalui proses tingkah laku yang dilalui seseorang. Maka dapat disimpulkan bahwa penyesuaian sosial adalah kemampuan seseorang dalam menyesuaikan diri dengan lingkungannya, baik terhadap orang lain maupun terhadap kelompok sosial.

Bimbingan kelompok teknik sosiodrama dapat digunakan untuk meningkatkan penyesuaian sosial siswa. Dilakukan melalui layanan bimbingan kelompok agar siswa memiliki pemahaman terhadap dirinya (potensi) dan lingkungannya. Dalam tahap kegiatan pada bimbingan kelompok, pimpinan kelompok memberikan naskah cerita yang akan diterapkan pada teknik sosiodrama. Naskah cerita menyesuaikan topik dari masalah yang dialami oleh siswa yang meliputi aspek-aspek penyesuaian sosial menurut [11] yaitu penampilan nyata, penyesuaian terhadap kelompok, sikap sosial dan kepuasan pribadi. 
sosiodrama pada dasarnya mendramatisasikan tingkah laku dalam hubungan dengan masalah sosial [12]. Untuk melaksanakan metode bermain peran, siswa harus memiliki kemampuan agar dapat mengetahui karakter dari peran yang akan dimainkan.

Hasil analisis data dengan menggunakan Uji Wilcoxon setelah pemberian perlakuan menunjukkan, teknik sosiodrama melalui layanan bimbingan kelompok efektif untuk meningkatkan penyesuaian sosial, artinya hasil postest mengalami peningkatan pada kategori tinggi. Hal tersebut ditunjukkan dengan adanya perbedaan dari hasil pretest dan hasil posttest, yang berarti bahwa teknik sosiodrama melalui layanan bimbingan kelompok untuk meningkatkan penyesuaian sosial siswa telah terpenuhi. Hasil penelitian ini senada dengan penelitian yang dilakukan oleh [13] yang menyimpulkan bahwa pemberian layanan bimbingan kelompok teknik sosiodrama dapat meningkatkan interaksi sosial siswa.

Penyesuaian sosial yang baik akan membuat kualitas hidup individu baik pula. Memiliki penyesuaian sosial yang baik akan memudahkan individu beradaptasi dan berinteraksi, menerima pendapat dan sikap individu lain, serta saling berbagi, sehingga individu akan memiliki tujuan hidup yang terarah, merasa aman dan bermanfaat dalam lingkungan sosialnya. Penyesuaian diri terhadap sosial dapat terlihat pada diri individu dalam hubungan komunikasi yang baik, saling menghormati, bertindak sesuai dengan norma yang berlaku di lingkungannya, dan menjalankan kewajiban dan hak-hak kelompok secara positif ditandai dengan kepercayaan diri terhadap diri sendiri dan orang lain [14].

Bimbingan kelompok teknik sosodrama didasarkan atas hasil analisis kebutuhan lapangan yang disesuaikan dengan kebutuhan siswa, sehingga diperlukan metode yang menarik dalam pemberian layanan bimbingan kelompok yang berkualitas dengan menerapkan dinamika kelompok melalui sosiodrama. Lumongga [15] menjelaskan, teknik sosiodrama memberi peluang mengekspresikan berbagai perasaan yang menekan anggota kelompok melalui suasana yang didramatisasikan sehingga klien dapat secara bebas mengungkapkan dirinya sendiri secara lisan, tulisan, atau melalui gerakan dramatis.

Sosiodrama membantu siswa dalam menyelesaikan masalah-masalah hubungan antar manusia, mampu menanamkan sikap demokratis, saling menghargai pendapat orang lain, serta mampu mengambil keputusan terbaik dalam sebuah kelompok [16]. Bimbingan kelompok dengan teknik sosiodrama berdampak positif dalam layanan bimbingan dan konseling di sekolah. Melalui bimbingan kelompok teknik sosiodrama, siswa mampu mengaktualisasikan dirinya, terbuka pada orang lain, dapat menerima informasi dan pengetahuan dari orang lain, saling berbagi, saling memotivasi dalam kebaikan, memiliki percaya diri, mendisiplinkan diri, bermanfaat untuk orang lain, memiliki tujuan hidup yang terarah, serta mampu menyesuaikan diri terhadap kelompok.

\section{KESIMPULAN}

Berdasarkan hasil uji analisis data, dari tahap pendahuluan, studi lapangan, uji coba instrumen, dan penerapan teknik sosiodrama, dapat ditarik beberapa kesimpulan:

1. Pelaksanaan bimbingan kelompok siswa kelas VIII di SMP Negeri 4 pasarwajo telah dilaksanakan, namun dalam tahap penelitian belum optimal dan efektif. Berdasarkan hasil posttest dengan 8 sampel, 3 siswa atau 37,5\% subyek dalam kategori sedang dan 5 siswa atau $62,5 \%$ subyek telah memiliki penyesuaian sosial yang tinggi atau baik.

2. Teknik sosiodrama melalui layanan bimbingan kelompok untuk meningkatkan penyesuaian sosial siswa, efektif untuk dilakukan didasarkan pada hasil postest yang meningkat, skor hasil prets yang meningkat 237 poin dan didukung dengan hasil uji Wilcoxon dengan probabilitas 0.012 .

SARAN

1. Pihak sekolah

Untuk dapat meningkatkan fasilitas sekolah dan layanan Bimbingan dan Konseling dengan melengkapi sarana dan prasarananya untuk meningkatkan penyesuaian sosial siswa.

2. Guru Bimbingan dan Konseling

Untuk dapat mengembangkan dan menindaklanjuti layanan bimbingan dan konseling melalui penerapan pendekatan ataupun teknik konseling yang lebih variatif, baik melalui layanan bimbingan kelompok, bimbingan individu, konseling kelompok maupun konseling individual.

3. Bagi peneliti selanjutnya

Penelitian ini diharapkan dapat memberi konstribusi dalam keilmuan bimbingan dan konseling terkhusus pada kajian layanan bimbingan kelompok dan teknik sosiodrama. Disamping itu, bagi peneliti yang akan melakukan penelitian tentang penyesuaian sosial dan teknik sosiodrma, agar dapat mengembangkan kajiannya pada aspek dan indikator yang lebih tampak pada siswa.

\section{DAFTAR PUSTAKA}

[1] Ahmad Susanto, M. P. (2018). Bimbingan dan Konseling di Sekolah: Konsep, Teori, dan Aplikasinya. Jakarta: Kencana.

[2] Pratiwi, E. P., Hanim, W., \& Badrujaman, A. (2017). Pengaruh Teknik Role Playing Dalam Bimbingan Kelompok Terhadap Toleransi Pada Peserta Didik Kelas X Smk Negeri 26 Jakarta. INSIGHT: Jurnal Bimbingan Konseling, 6(2), 114129.

[3] Sari, N. W., Yusmansyah, Y., \& Utaminingsih, D. (2014). Pengaruh Teknik Sosiodrama untuk Peningkatan Perilaku Asertif Siswa. ALIBKIN (Jurnal Bimbingan Konseling), 3(4), $1-10$. 
[4] Sugiyono. (2018). Metode Penelitian Pendidikan Pendekatan Kauntitatif, Kualitatif, $R \& D$. Bandung: Alfabeta.

[5] Sugiyono. (2012). Metode Penelitian Kuantitatif, Kualitatif dan $R \& D$. Bandung: Alfabeta.

[6] Azwar, S. (2012). Penyusunan Skala Psikologi, in Edisi 2. Yogyakarta: Pustaka Pelajar.

[7] Rangkuti, A. A. (2017). Statistika Inferensial untuk Psikologi dan Pendidikan. Jakarta: Kencana.

[8] Endra, F. (2017). Pedoman Metodologi Penelitian (Statistika Praktis). Sidoarjo: Zifatama Jawara.

[9] Ulfa, M. (2017). Hubungan Pola Asuh Demokratis Orang Tua, Konsep Diri, dan Penyesuaian Sosial Dengan Perilaku Asertif Siswa SMK Muhammadiyah 1 Sleman Yogyakarta. Sang Pencerah, 3(1), 71-81.

[10] Amaliah, R., \& Nasution, I. K. (2014). Gambaran Penyesuaian Sosial pada Remaja Penderita Sinusitis Kronis. Psikologia: Jurnal Pemikiran dan Penelitian Psikologi, 9(2).

[11] Hurlock, E. B. (2014). Perkembangan Anak Edisi Keenam Jilid I. Jakarta: Penerbit Erlangga.

[12] Bahri Djamarah, S., \& Zain, A. (2010). Guru dan Anak Didik dalam Interaksi Edukatif Suatu Pendekatan Teoritis Psikologis. Jakarta: Rineka Cipta.

[13] Hasibuan, R. E. (2018). Pengaruh Pemberian Layanan Bimbingan Kelompok Teknik Sosiodrama Terhadap Peningkatan Interaksi Sosial Oleh Siswa Kelas VIII MTS Amin Darussalam TA 2017/2018. Doctoral Dissertation UNIMED.

[14] Devine, K. A., Holmbeck, G. N., Gayes, L., \& Purnell, J. Q. (2011). Friendships of Children and Adolescents With Spina Bifida: Social Adjustment, Social Performance, And Social Skills. Journal of pediatric psychology, 37(2), 220-231.

[15] Lumongga, N. (2017). Konseling Kelompok. Jakarta: Kencana.

[16] Krissandi, A. D. S., Widharyanto, B., \& Dewi, R. P. (2018) Pembelajaran Bahasa Indonesia untuk SD: Pendekatan dan Teknis. T. Diman, Ed. Jakarta: Media Maxima. 